\title{
CIUDAD DE MÉXICO: DINÁMICA INDUSTRIAL Y ESTRUCTURACIÓN DEL ESPACIO EN UNA METRÓPOLI SEMIPERIFÉRICA
}

\author{
GuSTAVO GARZa \\ MARTHA SCHTEINGART
}

El Colegio de México

\section{INTRODUCCIÓN}

UNA VEZ QUE EL CAPITALISMO surge como hegemónico, la industrialización es la génesis de la concentración económico-demográfica en las ciudades, esto es, de la urbanización. Así, a cierto nivel de industrialización corresponde un desarrollo comercial, de servicios, de transportes y de otras actividades que surge de manera simultánea a un proceso de concentración de población: la fuerza de trabajo se desplaza hacia donde el capital se acumula.

El proceso de urbanización resultante se caracteriza por una tendencia hacia la elevada concentración económico-demográfica en una o unas cuantas ciudades o regiones. Esto se deriva de la construcción secular de un inmenso conjunto de condiciones generales de la producción (carreteras, energéticos, dotación de servicios urbanos, etc.) que constituyen un importante capital socializado, que al concentrarse en una ciudad o región permite obtener mayores tasas de ganancia a las empresas que en ellas se ubican, creando, de esta manera, una tendencia hacia la elevada concentración económico-espacial en las 
economías capitalistas desarrolladas o subdesarrolladas (véase Garza, 1983).

La aglomeración de una parte significativa de actividades económicas y de población en una gran ciudad, acarrea una compleja problemática social que se vincula con los procesos de asentamiento y las necesidades de consumo de los diferentes estratos poblacionales. La acción de los agentes capitalistas involucrados en estos procesos, y sobre todo la del Estado, es fundamental en la determinación de la organización del espacio y el crecimiento del centro urbano.

Por otra parte, en la presente etapa de internacionalización del capital, algunas de las principales metrópolis se transforman en verdaderos centros geopolíticos o espacios de poder y estructuran un nuevo sistema de integración espacial regido por capitales de carácter supranacional. Según este proceso, se pueden delimitar tres niveles de inflúencia regional de una ciudad: en el área de los países centrales, . en los semiperiféricos o en los periféricos.

Existe un número reducido de ciudades con área de influencia en los tres niveles que conforman el núcleo del sistema territorial mundial; algunos autores las denominan ciudades mundiales (Friedmann y Wolff, 1982; Hall, 1977). En este tipo de ciudades, Friedmann y Wolff incluyen algunas urbes de la periferia, como la ciudad de México, a diferencia de Hall que sólo considera dentro de esa caracterización a las principales metrópolis de los países centrales.

En el presente artículo se analiza, dentro del contexto de los anteriores planteamientos, el proceso de concentración industrial en la ciudad de México, con relación a algunas características de la estructuración del espacio interno metropolitano. Se intenta, también, determinar sí la ciudad de México puede catalogarse como ciudad mundial y hasta qué punto su inserción en la economía internacional influye sobre su dinámica económica y sus características socioespaciales.

\section{$\left[\begin{array}{l}\text { EL PROCESO DE INDUSTRIALIZACIÓN } \\ \text { DE LA CIUDAD DE MÉXICO }\end{array}\right]$}

E El desarrollo industrial mexicano es el resultado de un patrón de acumulación de capital basado en la sustitución de importaciones, medida que se inicia alrededor de los años treinta y que, bajo diversas modalidades, continuó hasta agotar sus posibilidades o desembocó en la profunda crisis económica actual.

El crecimiento económico en las cinco décadas que van de 1930 a nuestros días ha sido importante. El producto interno bruto (PIB) total entre 1930-1940 aumentó en términos reales al 3.1\% anual; al 
$5.9 \%$ entre $1940-1950$; al $6.2 \%$ en $1950-1960$; y continuó avanzando hasta alcanzar el $7.0 \%$ anual entre $1960-1970$ y el $6.6 \%$ anual entre 1970-1980.

Este considerable desarrollo de la producción fue significativamente impulsado por el sector secundario, y, particularmente, por la industria de transformación. La dinámica de crecimiento de esta última fủe creciente y con tasas más elevadas que el PIB total: $5.0 \%$ anual para $1930-1940 ; 7.1 \%$ anual en $1940-1950 ; 7.3 \%$ entre $1950-1960$; $8.9 \%$ entre $1960-1970$; y $6.3 \%$ entre $1970-1980$.

La estructuración espacial de este desarrollo se caracterizó por la concentración de la producción industrial en la ciudad de México. Fue ésta la urbe más favorecida por la industrialización interna -lo cual explica, en gran medida, su dinámica de crecimiento, sin que por ello se haya transformado en un importante centro mundial de decisiones. Más bien se articula en forma subordinada a los centros de dominación de los paises hegemónicos.

\section{Hacia la superconcentración industrial}

En 1930 el país contaba con 46830 establecimientos industriales, de los cuales únicamente $3180(6.8 \%)$ se localizaban en la ciudad de México. Su número aumentó a medida que avanzaba el proceso de industrialización, y se alcanzó en 1970 la cifra de 118993 en la República y 33185 en la capital.

Según el valor agregado industrial, la capital del país aumenta de manera ininterrumpida su participación en la industria nacional: $27.2 \%$ en $1930,30.8 \%$ en $1940,43.6 \%$ en $1950,47.1 \%$ en $1960 \mathrm{y}$, finalmente, $48.6 \%$ en 1970 (véase cuadro 1). ${ }^{1}$ Este proceso de concentración territorial de la industria mexicana en lo que va del siglo, dio por resultado la superconcentración de la producción en 1970: 18286 millones de pesos en la ciudad de México, contra $19337 \mathrm{mi}$ llones en el resto del país. De este modo, una sola ciudad del sistema

1 El último censo realizado en el país es el de 1975; en el presente trabajo no se incluyen los datos recabados en ese año, pues se han utilizado únicamente los de los censos decenales y aún no se han presentado los resultados del de 1980. Según el censo de 1975 , en la ciudad de México se concentra el $45.4 \%$ de la industria nacional, pero este dato no es comparable con los de años anteriores por no haberse aún realizado los ajustes necesarios para efectuar dicha comparabilidad. (La metodología para la comparabilidad de los censos de $1930,1940,1950,1960$ y 1970 puede verse en G. Garza, 1983; Apéndice Metodológico I.) 
Cuadro 1. Ciudad de México: participación en la industria nacional según valor agregado y sectores industriales, 1930-1970

\begin{tabular}{llllll}
\hline Sectores $y$ grupos industriales & 1930 & 1940 & 1950 & 1960 & 1970 \\
\hline Total & 27.2 & 32.8 & 40.4 & 47.1 & 48.6 \\
I. Medios de producción & 27.6 & 40.1 & 40.9 & 36.3 & 40.5 \\
I.1. Bienes de capital & 63.1 & 94.0 & 58.8 & 54.7 & 66.4 \\
35. Productos metálicos & 62.7 & 98.7 & 61.3 & 52.4 & 68.5 \\
36. Maquinaria no eléctrica & 76.1 & 45.2 & 50.0 & 63.4 & 62.0 \\
1.2. Bienes intermedios & 25.3 & 36.7 & 36.3 & 32.8 & 32.0 \\
25. Madera y corcho & 32.7 & 70.8 & 37.4 & 10.7 & 12.0 \\
27. Celulosa y papel & 30.5 & 47.4 & 49.8 & 46.1 & 46.8 \\
32. Productos de petróleo y carbón & 00.0 & 32.0 & 34.4 & 27.3 & 29.5 \\
33. Minerales no metálicos & 42.5 & 34.0 & 35.3 & 35.4 & 36.4 \\
34. Metálicos básicos & 19.9 & 24.3 & 31.6 & 33.1 & 28.2 \\
I1. Medios de consumo & 27.1 & 30.8 & 40.2 & 51.6 & 52.6 \\
II.1. Bienes de consumo inmediato & 26.7 & 28.9 & 37.8 & 47.3 & 50.1 \\
20. Alimentos & 23.3 & 17.2 & 21.1 & 26.3 & 32.3 \\
21. Bebidas & 14.7 & 35.8 & 38.2 & 41.7 & 31.9 \\
22. Tabaco & 51.5 & 31.0 & 26.7 & 23.7 & 24.9 \\
23. Textiles & 13.0 & 19.3 & 28.7 & 38.2 & 45.5 \\
24. Calzado y vestuario & 48.7 & 46.4 & 51.8 & 66.7 & 60.2 \\
28. Imprentas & 78.5 & 69.1 & 73.2 & 81.4 & 85.6 \\
29. Cuero y piel & 38.2 & 39.2 & 44.9 & 62.2 & 54.4 \\
30. Productos de hule & 67.6 & 85.2 & 85.1 & 88.6 & 88.9 \\
31. Química & 52.2 & 60.9 & 67.5 & 77.8 & 66.6 \\
II.2. Bienes de consumo duradero & 46.3 & 76.7 & 65.9 & 79.0 & 62.9 \\
26. Mnebles & 40.3 & 73.7 & 70.2 & 68.5 & 66.3 \\
37. Artículos eléctricos & 79.0 & 38.7 & 54.4 & 77.7 & 75.0 \\
38. Automotriz & 27.3 & 72.7 & 60.7 & 90.6 & 49.2 \\
39. Otras industrias & 48.6 & 95.1 & 83.3 & 65.8 & 70.1 \\
\hline
\end{tabular}

Fuente: Garza, Gustavo, El proceso de industrialización de la ciudad de México (1821-1970). Condiciones Generales de la producción y concentración espacial en el capitalismo, Centro de Listudios Demográficos y de Desarrollo Urbano, lil Colcgio de México, Méx- 
urbano nacional produce casi la mitad de los artículos industriales de la nación. Adicionalmente, aunque entre 1960-1970 su participación aumentó únicamente $1.5 \%$ (de $47.1 \%$ a $48.6 \%$ ), su producción industrial absoluta prácticamente se triplicó en esos diez años, por lo que un aumento relativamente ligero en su concentración respecto del resto del país, implica una cuantiosa multiplicación de su aparato industrial.

Es probable que este elevado nivel de concentración haya alcanzado su límite superior, y en el futuro inmediato se reduzca en términos relativos; sin embargo, si continúa la libre localización de las empresas, la concentración industrial territorial proseguirá en términos absolutos en la ciudad de México, y le imprimirá una dinámica económica que sobrepase abrumadoramente al resto de ciudades del sistema urbano mexicano. Así, el aumento de la producción bruta industrial de la ciudad entre 1960-1970, es igual a la producción total industrial de 1970, esto es, la que alcanzaron, a lo largo de todo su desarrollo histórico, las 10 ciudades que le siguen en importancia industrial: Monterrey, Guadalajara, Toluca, Puebla, Torreón, Monclova, Veracruz, Chihuahua, Querétaro y Ciudad Sahagún (la información referente a estas ciudades puede verse en Garza, 1980, 88).

En un trabajo anterior, se ha realizado un sencillo ejercicio prospectivo del proceso de industrialización de la ciudad de México hasta el año 2000 (Garza, 1981). Se supone, como posibilidad más realista, que la disminución relativa observada en la información relativamente confiable de 1975 , continuará y la participación de la ciudad será del $44.4 \%$ en 1980 , del $42.4 \%$ en 1990 y del $40.4 \%$ en el año 2000.2 De acuerdo con los valores estimados en ese trabajo para la producción industrial nacional, y con base en los anteriores porcentajes, la zona metropolitana de la ciudad de México tendrá una producción industrial real de 65422 millones de pesos en 1980, de 137400 en 1990 y de 287917 millones de pesos en el año 2000. De esta forma, la producción industrial de la capital del país aumentará el $440 \%$ en los 20 años comprendidos entre 1980-2000 (Garza, 1981, 110).

De esta suerte, aunque en los próximos años ocurra una desaceleración relativa del proceso de concentración industrial en la ciudad

2 Esto es probable por dos razones: i) la elevada masa industrial alcanzada por la ciudad de México impedirá que continúe creciendo indefinidamente a tasas elevadas, y es lógico esperar una disminución relativa; ii) con el proceso de acumulación de capital se impone la necesidad de la expansión territorial de las fuerzas productivas, lo cual implica una disminución de la concentración en una sola metrópoli. 
de México, esto no significará, en modo alguno, la terminación de su crecimiento industrial en términos absolutos. Éste continuará hasta triplicar su producción industrial de 1980, y seguramente la de los otros sectores económicos, y su población será de alrededor de 30 millones de habitantes en el año 2000.

En forma paralela, la necesidad de expansión territorial del capital ha hecho imprescindible el desarrollo de la explotación de los recursos naturales y de la fuerza de trabajo en otras regiones del pais, con lo cual se ha ampliado el mercado interno nacional, el que, hoy por hoy, es la única posibilidad de continuar el proceso de crecimiento económico. De mantenerse las estructuras económico-sociales actuales surgirá un proceso de concentración en una o unas cuantas regiones creando nuevos ámbitos territoriales de concentración, sin que ello modifique esencialmente la tendencia hacia la concentración espacial. Es por esto que en las economías capitalistas desarrolladas ha surgido el fenómeno de la concentración económico-demográfica en megalópolis. 3

En México se ha observado que el ritmo de la concentración se reduce. Entre 1960-1970 su nivel sólo aumentó el 1.5\%, y no hay que perder de vista que había crecido $3.5 \%$ entre $1950-1960 ; 13.8 \%$ entre 1940-1950 y 3.6\% entre 1930-1940. Esta disminución en el crecimiento de la importancia relativa de la ciudad de México, se presenta de manera paralela al aumento de la participación de su región geoeconómica. Existe la tendencia a conformar, al parecer, un nuevo ámbito de concentración en el país. La región Centro-Oeste, constituida por las entidades de Querétaro, México, Distrito Federal, Morelos, Hidalgo, Tlaxcala y Puebla, constituye la zona de influencia inmediata de la ciudad de México (Bassols Batalla, 1979, 449). En esta región, la participación relativa de la industria de transformación aumenta ligeramente: del $59.3 \%$ en 1965 , al $59.9 \%$ en 1970 y al $60.0 \%$ en 1975 (Magalhaes Cordeiro, 1982, 72).

Dentro de la región Centro-Oeste, la ciudad de México se ha constituido en el núcleo de un subsistema articulado de ciudades entre las que sobresalen: Puebla, Querétaro, Toluca, Cuernavaca y Pachuca

${ }^{3}$ Como ejemplos se pueden citar la megalópolis Tokaido, que comprende al conglomerado urbano entre Tokio-Nagoya-Osaka, en Japón (Glickman, 1977); la megalópolis Boston-Nueva York-Filadelfia-Baltimore-Washington, en la costa noreste de los Estados Unidos de América (Gottmann, 1961); la concentración metropolitana de la región del Gran París, en el Valle Brisience (Thompson, 1973) y la megalópolis del centro de Gran Bretaña, que va desde Londres hasta las regiones metropolitanas de Birmingham, Nottingham, Liverpool y Manchester (Broadbent, 1977; Bourne, 1975). 


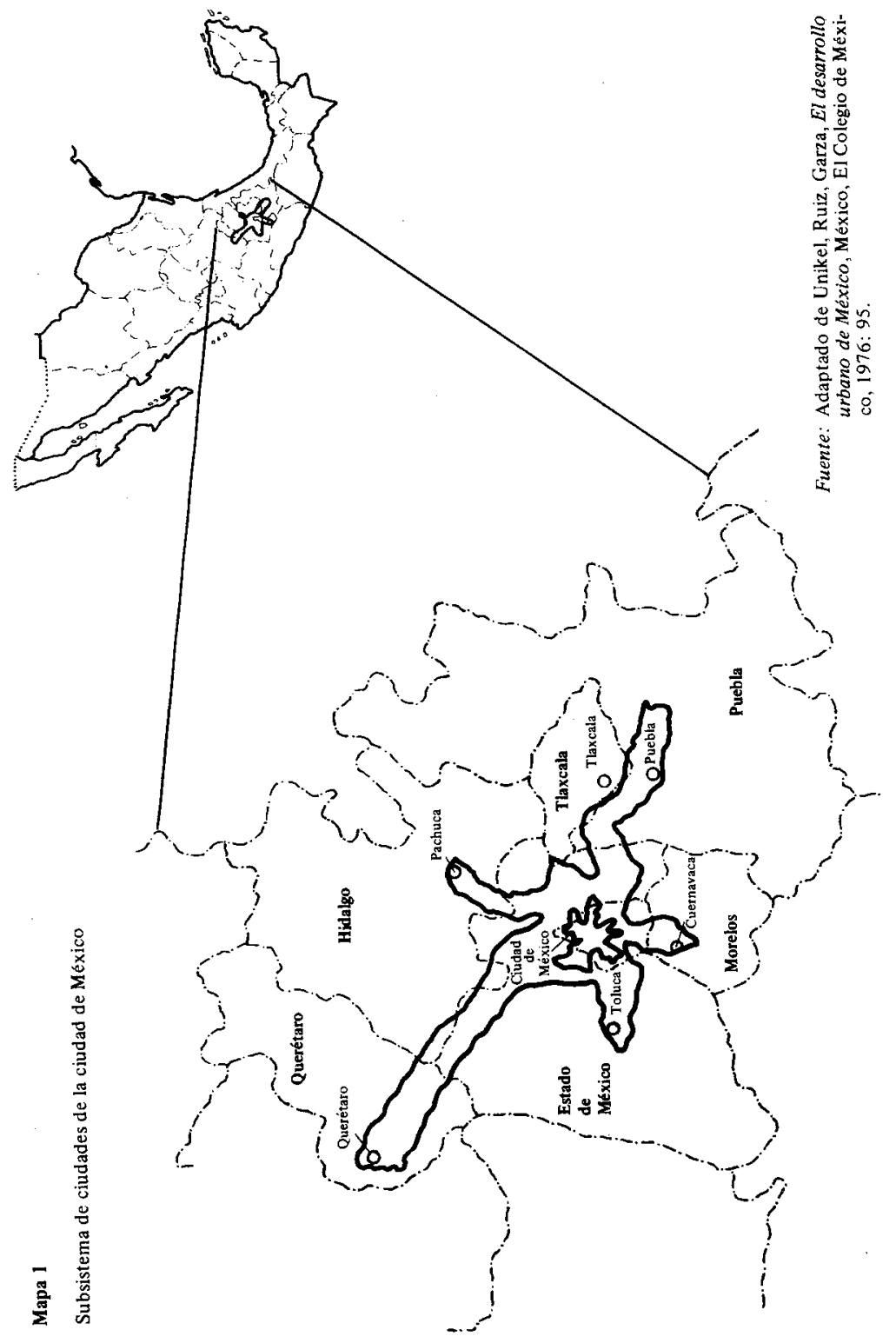


(véase mapa 1). En la actualidad, las zonas metropolitanas de la ciudad de México y de Toluca se encuentran unidas, por lo que técnicamente constituyen la primera megalópolis latinoamericana. En lo que resta del presente siglo, se agregarán a ésta las zonas metropolitanas de Cuernavaca y Puebla y, posteriormente, la de Querétaro. Se consolidará asi una densa megalópolis que multiplicará aceleradamente los requerimientos de inversión pública y producirá, al mismo tiempo, una problemática de enorme complejidad y de consecuencias económicas, políticas y sociales imprevisibles.

\section{Diversificación de la estructura industrial}

El desarrollo industrial alcanzado entre 1930-1970, vía sustitución de importaciones, se divide en dos etapas: la primera, de "industrialización sustitutiva fácil de bienes de consumo inmediato", que va de 1930 a 1950 y la segunda, "sustitutiva de bienes de consumo duradero o intermedios", que va de 1950 hasta la actualidad.

El patrón de acumulación vía sustitución de importaciones fue viable gracias a la dirección del Estado Mexicano, el cual estableció una serie de políticas económicas para favorecerlo.

El crecimiento económico modificó la estructura de la producción nacional en favor de las actividades secundarias y, principalmente, de la industria de transformación. Esta última elevó su importancia relativa al crecer de $12.9 \%$ del PIB nacional en 1930 , al $17.1 \%$ en 1950 , al $22.5 \%$ en 1970 y al $23 \%$ en 1980 . Así, la estructura interna del sector industrial sufrió cambios importantes durante el proceso de sustitución de importaciones.

El análisis comparativo de la estructura industrial nacional y la de la ciudad de México, es un paso necesario para estudiar la localización espacial de las industrias en el país, y para comprender los determinantes y características de la organización territorial de las actividades económicas.

Durante la etapa de sustitución de bienes de consumo inmediato (1930-1950), la estructura industrial de la capital de la República mostró diferencias significativas con respecto al resto del país: $i$ ) en 1930 la ciudad tenía alrededor del doble de la participación de bienes de capital y de consumo duradero; ii) en contrapartida, tenía menor participación en los bienes de consumo inmediato e intermedio. $\mathrm{Ob}$ viamente, estos últimos eran también los principales subsectores, y absorbian el $95.3 \%$ del total de su producción industrial. La ciudad presentaba, no obstante, la tendencia a especializarse en bienes de capital y de consumo duradero; iii) para 1940 dichos subsectores adquieren mayor participación en la ciudad, situación que se mantie- 
ne hasta 1950, aunque disminuyen sus diferencias respecto al resto del país (véanse cuadros 2 y 3 ).

En la etapa de sustitución de bienes de consumo duradero e intermedio (1950-1970), la tendencia anterior persiste: $i$ ) la diferencia, aunque menor, se mantiene en los de consumo duradero; los de capital siguen, con mayores porcentajes, representando en 1970 el $8.1 \%$ del total de la industria nacional, y en la ciudad el $11.1 \%$ de la industria capitalina; ii) la participación en 1970 es muy semejante para los bienes de consumo inmediato; le corresponde el $54.4 \%$ en la nación y el $56.1 \%$ en la ciudad; iii) todo se compensa por la baja participación de la producción de bienes intermedios en la ciudad, los cuales representaban en 1970 sólo el $16.3 \%$, mientras que en el país lo representan el $24.8 \%$ (véanse cuadros 2 y 3 ).

Según el análisis de la estructura industrial, se concluye que existe una especialización, o ventaja locacional, de la ciudad de México en la producción de bienes de consumo duradero y de capital, y una desventaja en la de bienes intermedios. Los bienes de consumo inmediato presentan un adecuado equilibrio en su distribución territorial entre la ciudad de México y el resto del país. De aquí, se suele inferir que los primeros bienes de consumo duradero y de capital, requieren de las grandes economías de escala y de urbanización, del mercado, de la fuerza del sector público, etc., que existen en la principal ciudad de la República.

La acelerada industrialización de la ciudad de México en el periodo 1930-1970, no significó una mayor diversificación de su estructura industrial; así pues, persistieron diez grupos industriales con elevada participación en la producción nacional. De esta suerte, la ciudad de México mantiene en este lapso su supremacía como productora de bienes de capital, en cuya producción se especializa como primer centro industrial nacional.

La especialización en este tipo de bienes conlleva una mayor dependencia de las empresas transnacionales. ${ }^{4}$ En efecto, para 1970 éstas participan con el $35.9 \%$ de la producción total de bienes de capital, y puesto que estos últimos se concentran en un $66.4 \%$ en la ciudad de México, resulta que tales empresas controlan el $4.0 \%$ de

4 Se consideran como empresas transnacionales a aquellas cuya participación de capital extranjero permite suponer que éste puede ejercer un control efectivo sobre su gestión. En el estudio en que se basan los porcentajes de participación de las transnacionales, se utilizó el 15\% como el porcentaje "crítico" a partir del cual la empresa se consideró filial de alguna transnacional (Fajnzylber y Martínez, 1976:150). 
Cuadro 2. República Mexicana: estructura industrial según valor agregado, 1930-1970 (en miles de pesos de $1950=100$ )

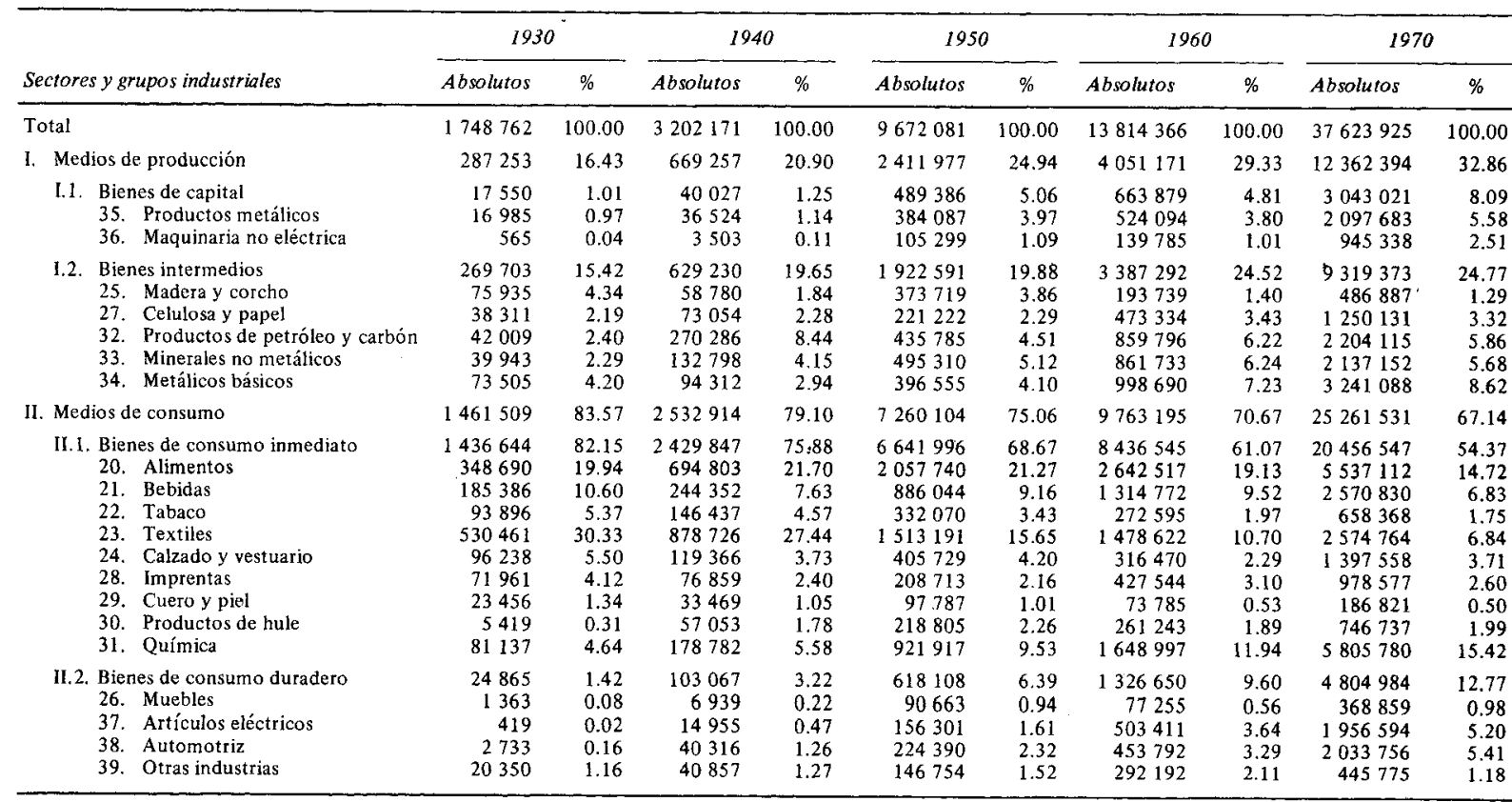

Fuente: Garza, Gustavo, ibidem, cuadro V1-4, p. 221. 
Cuadro 3. Ciudad de México: estructura industrial según valor agregado, 1930-1970

(en miles de pesos de $1950=100$ )

\begin{tabular}{|c|c|c|c|c|c|c|c|c|c|c|}
\hline \multirow[b]{2}{*}{ Sectores y grupos industriales } & \multicolumn{2}{|c|}{1930} & \multicolumn{2}{|c|}{1940} & \multicolumn{2}{|c|}{1950} & \multicolumn{2}{|c|}{1960} & \multicolumn{2}{|c|}{1970} \\
\hline & Absolutos & $\%$ & Absolutos & $\%$ & Absolutos & $\%$ & Absolutos & $\%$ & Absolutos & $\%$ \\
\hline Total & 474890 & 100.00 & 1048815 & 100.00 & 3904482 & 100.00 & 6513086 & 100.00 & 18286602 & 100.00 \\
\hline I. Medios de producción & 79181 & 16.67 & 268434 & 25.59 & 985829 & 25.25 & 1472540 & 22.61 & 5005437 & 27.37 \\
\hline $\begin{array}{l}\text { 1.1. Bienes de capital } \\
\text { 35. Productos metálicos } \\
\text { 36. Maquinaria no eléctrica }\end{array}$ & $\begin{array}{r}11080 \\
10650 \\
430\end{array}$ & $\begin{array}{l}2.33 \\
2.24 \\
0.09\end{array}$ & $\begin{array}{r}37616 \\
36032 \\
1584\end{array}$ & $\begin{array}{l}3.58 \\
3.43 \\
0.15\end{array}$ & $\begin{array}{r}287917 \\
235295 \\
52622\end{array}$ & $\begin{array}{l}7.37 \\
6.02 \\
1.35\end{array}$ & $\begin{array}{r}363169 \\
274495 \\
88674\end{array}$ & $\begin{array}{l}5.58 \\
4.22 \\
1.36\end{array}$ & $\begin{array}{r}2022067 \\
1435961 \\
586106\end{array}$ & $\begin{array}{r}11.06 \\
7.85 \\
3.21\end{array}$ \\
\hline $\begin{array}{l}\text { I.2. Bienes intermedios } \\
\text { 25. Madera y corcho } \\
\text { 27. Celulasa y papel } \\
\text { 32. Productos de petróleo y carbón } \\
\text { 33. Minerales no metálicos } \\
\text { 34. Metálicos básicos }\end{array}$ & $\begin{array}{l}68101 \\
24849 \\
11696 \\
1690 \\
14597 \\
1459\end{array}$ & $\begin{array}{r}14.34 \\
5.23 \\
2.46 \\
0.00 \\
3.57 \\
3.08\end{array}$ & $\begin{array}{r}230818 \\
41636 \\
34600 \\
86460 \\
45178 \\
22944\end{array}$ & $\begin{array}{r}22.01 \\
3.97 \\
3.30 \\
8.24 \\
4.31 \\
2.19\end{array}$ & $\begin{array}{l}697912 \\
139779 \\
108564 \\
149751 \\
174621 \\
125197\end{array}$ & $\begin{array}{r}17.88 \\
3.58 \\
2.78 \\
3.84 \\
4.47 \\
3.21\end{array}$ & $\begin{array}{r}1109371 \\
20641 \\
218029 \\
235133 \\
304795 \\
330773\end{array}$ & $\begin{array}{r}17.03 \\
0.31 \\
3.35 \\
3.61 \\
4.68 \\
5.08\end{array}$ & $\begin{array}{r}2983370 \\
58283 \\
58544 \\
649408 \\
778273 \\
912862\end{array}$ & $\begin{array}{r}16.31 \\
0.32 \\
3.20 \\
3.55 \\
4.25 \\
4.99\end{array}$ \\
\hline II. Medios de consumo & 395709 & 83.33 & 780381 & 74.41 & 2918653 & 74.75 & 5040546 & 77.39 & 13281165 & 72.63 \\
\hline $\begin{array}{l}\text { 11.1. Bienes de consumo inmediato } \\
\text { 20. Alimentos } \\
\text { 21. Bebidas } \\
\text { 22. Tabaco } \\
\text { 23. Textilies } \\
\text { 24. Calzado } y \text { vestuario } \\
\text { 28. Imprentas } \\
\text { 29. Cuero y piel } \\
\text { 30. Productos de hule } \\
\text { 31. Química }\end{array}$ & $\begin{array}{r}384191 \\
81243 \\
27168 \\
48352 \\
69086 \\
46878 \\
56508 \\
8959 \\
3661 \\
42336\end{array}$ & $\begin{array}{r}80.90 \\
17.11 \\
5.72 \\
10.18 \\
14.55 \\
9.87 \\
11.90 \\
1.89 \\
0.77 \\
8.91\end{array}$ & $\begin{array}{r}701296 \\
119451 \\
87476 \\
45465 \\
169840 \\
55439 \\
53083 \\
13107 \\
48587 \\
108848\end{array}$ & $\begin{array}{r}66.87 \\
11.39 \\
8.34 \\
4.34 \\
16.19 \\
5.29 \\
5.06 \\
1.25 \\
4.63 \\
10.38\end{array}$ & $\begin{array}{r}2511539 \\
434838 \\
33406 \\
88562 \\
43460 \\
210308 \\
152711 \\
43886 \\
186133 \\
622035\end{array}$ & $\begin{array}{r}64.32 \\
11.14 \\
8.67 \\
2.27 \\
11.13 \\
5.38 \\
3.31 \\
1.12 \\
4.77 \\
15.93\end{array}$ & $\begin{array}{r}3992930 \\
695509 \\
548869 \\
64533 \\
564331 \\
211009 \\
348147 \\
45879 \\
231394 \\
1283059\end{array}$ & $\begin{array}{r}61.31 \\
10.68 \\
8.43 \\
0.99 \\
8.67 \\
3.24 \\
5.35 \\
0.70 \\
3.55 \\
19.70\end{array}$ & $\begin{array}{r}10256531 \\
1786931 \\
818824 \\
164158 \\
1172368 \\
841971 \\
837648 \\
101589 \\
663799 \\
3869313\end{array}$ & $\begin{array}{r}56.09 \\
9.77 \\
4.48 \\
0.90 \\
6.41 \\
4.60 \\
4.58 \\
0.56 \\
3.63 \\
21.16\end{array}$ \\
\hline $\begin{array}{l}\text { 11.2. Bienes de consumo duradero } \\
\text { 26. Muebles } \\
\text { 37. Attículos eléctricos } \\
\text { 38. Automotriz } \\
\text { 39. Otras industrias }\end{array}$ & $\begin{array}{r}11518 \\
549 \\
331 \\
747 \\
9891\end{array}$ & $\begin{array}{l}2.43 \\
0.12 \\
0.07 \\
0.16 \\
2.08\end{array}$ & $\begin{array}{r}79085 \\
5114 \\
5784 \\
29327 \\
38860\end{array}$ & $\begin{array}{l}7.54 \\
0.49 \\
0.55 \\
2.80 \\
3.70\end{array}$ & $\begin{array}{r}407114 \\
63085 \\
84973 \\
136193 \\
122263\end{array}$ & $\begin{array}{r}10.43 \\
1.63 \\
2.18 \\
3.49 \\
3.13\end{array}$ & $\begin{array}{r}1047616 \\
52901 \\
391327 \\
411109 \\
112279\end{array}$ & $\begin{array}{r}16.08 \\
0.81 \\
6.01 \\
6.31 \\
2.95\end{array}$ & $\begin{array}{l}3024634 \\
244644 \\
1467355 \\
1000148 \\
312487\end{array}$ & $\begin{array}{r}16.54 \\
1.34 \\
8.02 \\
5.47 \\
17\end{array}$ \\
\hline
\end{tabular}


la producción industrial total de la metrópoli, mientras que en el resto del país, ese controł cubre sólo $1.8 \%$ de la producción.

Por lo que respecta a las industrias de bienes intermedios, la ciudad de México participa en forma elevada sólo en la fabricación de celulosa, papel y cartón, sector que mantiene una alta concentración entre $1940(47.4 \%)$ y $1970(46.8 \%)$. Las empresas transnacionales controlan el $32.1 \%$ de la producción nacional de bienes intermedios, y la capital del país participa con el $32.0 \%$, por lo que el dominio de la producción total, por lo que se refiere a estos bienes es $5.2 \%$, menor que en el resto del pais (10.5 por ciento).

Los bienes de consumo inmediato se orientan, en cierta medida, por la influencia de factores relacionados con las materias primas y el mercado local. Las industrias vinculadas a las materias primas, tales como la alimentación, bebidas, tabaco y textiles, presentan en la ciudad, en 1970, una participación menor que la del promedio del $48.6 \%$. Por el contrario, las relacionadas con el mercado local, tales como la editorial, de calzado y vestido, de productos de hule y sustancias y productos químicos (pinturas, jabones, perfumes, etc.), presentan elevados porcentajes (véase cuadro 1). Por lo que respecta a la totalidad del país, las transnacionales participan con el $30.2 \%$ de la producción de bienes de consumo inmediato, lo cual, si se aplica a los valores de la ciudad de México, significa que su influencia alcanza el $16.9 \%$ del total de su producción, mientras que en la del resto del país es del 15.9 por ciento.

Finalmente, los bienes de consumo duradero, considerados de manera convencional, como orientados hacia las "economías externas", "economías de urbanización", y el mercado, presentan elevadas concentraciones. Sobresale la producción de aparatos eléctricos, con el $75.0 \%$ del total ncional; la fabricación y ensamble de vehículos y automóviles, que absorbe el $49.2 \%$, y la producción de joyas, relojes, cámaras, etc. (otras industrias), con el $70.1 \%$ en 1970 (véase cuadro 1).

En lo que se refiere a estos bienes, las transnacionales tienen una injerencia del $61.5 \%$ de la producción nacional; del $10.2 \%$ de la producción total de la ciudad de México y del $5.6 \%$ de la total correspondiente al resto del país.

En síntesis, las empresas transnacionales dominan el $36.3 \%$ de la producción industrial total de la ciudad y en el $33.7 \%$ del resto del país pero, puesto que la totalidad de esta producción se destina al mercado interno nacional, la ciudad se puede clasificar más como metrópoli de la zona semiindustrializada del planeta, que como ciudad mundial propiamente dicha, como se verá en la última sección del trabajo. 
$\sqrt{\text { PROCESOS SOCIALES Y ESTRUCTURACIÓN DEL ESPACIO }}$ EN LA CIUDAD DE MÉXICO

Crecimiento urbano y empleo

FEl desarrollo industrial de la ciudad de México, al que acabamos de hacer referencia, se ha visto acompañado por la expansión de otras actividades económicas (el comercio y los servicios), y por la conformación de una nueva estructuración de las clases sociales, gracias a la aparición de nuevos grupos y la transformación o la expansión de los ya existentes, lo cual es aplicable tanto a la clase media como al proletariado urbano.

La población económicamente activa ocupada en el sector industrial, aumenta de $30.6 \%$ de la población activa en 1940, al $38.5 \%$ de la misma en 1970, aunque desciende relativamente entre 1960 y 1970. La población empleada en el sector comercio, en cambio, desciende del $26.8 \%$ en 1940 , al $13.5 \%$ en 1970 . El sector que presenta un mayor crecimiento en el empleo, es el de servicios, el cual crece de 28.9 a 36.5 por ciento.

Así, la estructura de la población económicamente activa de la ciudad de México se modifica, entre 1940 y 1970 , y se concentra más en la industria y los servicios, en detrimento del comercio y los transportes.

La gran expansión de los aparatos del Estado y la aparición de nuevos contingentes de funcionarios públicos que pasan a engrosar los grupos de clase media, incide en el crecimiento del empleo en el sector servicios. Sin embargo, también se incluyen en él, trabajos de baja productividad, los cuales traen consigo bajos ingresos y son representativos del llamado subempleo urbano.

Las transformaciones económicas y sociales consideradas hasta aquí traen aparejado un rápido crecimiento de la población de la ciudad, y ésta pasa de 1670314 habitantes en 1940 a 14445000 en 1980 , presentando altas tasas de crecimiento anual que oscilan de $5.2 \%$ a $5.9 \%$ durante un largo periodo, y descienden a menos de $5.0 \%$ en los últimos años (véase cuadro 4). Por otra parte, el área urbana se expandió violentamente hasta abarcar $117 \mathrm{~km}^{2}$ en 1940 , y más de $1000 \mathrm{~km}^{2}$ en 1980, atravesando un proceso de metropolización que ha cubierto las 16 delegaciones del Distrito Federal y 16 municipios del Estado de México.

Así, el área urbanizada de la ciudad se ubica en dos entidades federativas, y en ella convergen las autoridades de dos gobiernos locales, lo cual, a la larga, afectará los procesos de intervención de los 
organismos públicos, sobre las decisiones de planificación y las posibilidades de participación popular.]

\section{Ocupación del espacio: 1940-1960}

Entre 1940 y 1960 , la creciente población trabajadora se ubicó de manera más o menos adecuada, en los sectores industrial y de servicios. Esta concentración de mano de obra barata y las múltiples obras públicas realizadas en la capital, constituyeron las fuerzas productivas fundamentales que impulsaron su desarrollo industrial capitalista. El gasto público se dirigió preferentemente hacia obras que satisfacieran más las demandas del capital que las de la población trabajadora. Los migrantes que pasaron a formar parte de esta población, se ubicaron principalmente cerca de la zonas industriales (al norte de la ciudad), en colonias populares con escasos servicios y viviendas precarias. A principios de los cincuenta, las áreas centrales también recibieron parte de la corriente migratoria, con la consecuente saturación de las "vecindades" ubicadas en las zonas más antiguas y deterioradas (véase mapa 2).

Las clases media y alta, al verse presionadas por la expansión del aparato burocrático del Estado y de las actividades comerciales y de servicios, se desplazaron hacia las zonas periféricas del oeste y el sur del Distrito Federal, y también, a fines de los cincuenta, hacia el noroeste de la ciudad, ya en el Estado de México. En estas áreas residenciales se ubicaron también los nuevos contigentes de clase media que ascendieron gracias a la expansión de las actividades terciarias. Es principalmente para estos grupos que el Estado estructuró nuevos programas habitacionales, los cuales, si bien no fueron muy importantes, representaron un aumento significativo de la producción en la que participó el sector público. En cambio, para los sectores populares (proletariado y subproletariado), casi no existieron programas oficiales.

La mancha urbana, que casi se triplicó entre 1940 y 1960 , conlleva la descentralización creciente de las actividades productivas, comerciales y de servicios, así como la suburbanización de algunos sectores sociales que comenzaron a formar nuevos barrios, fácilmente distinguibles por su localización y nivel de servicios. Se crearon nuevos espacios urbanos que sentaron las bases para una creciente segregación interna de la ciudad. 
Mapa 2

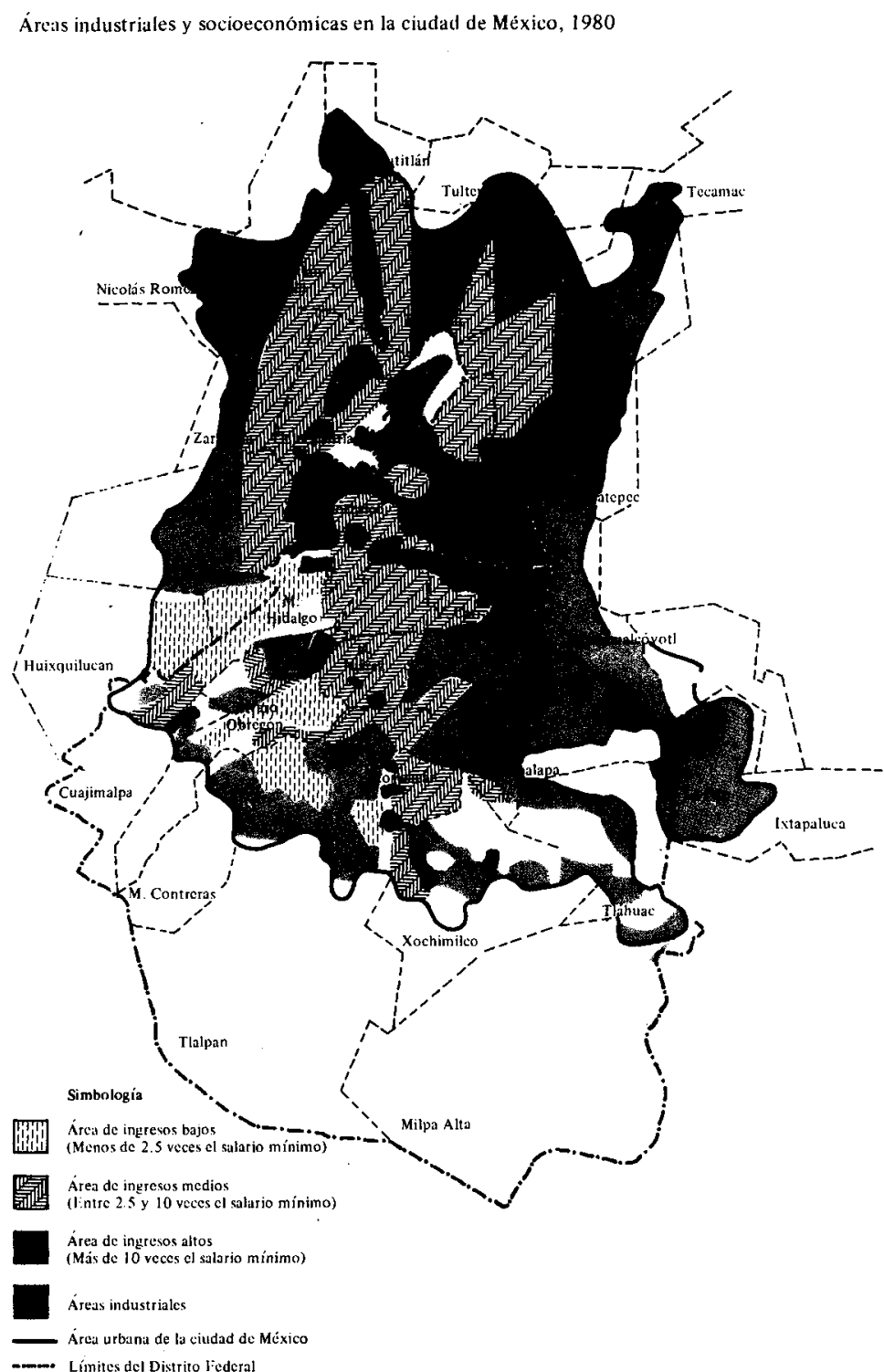


Expansión acelerada: $1960-1980$

En la década de los años sesenta, tiene lugar una enorme expansión del área urbana, sobre todo en el Estado de México, y se producen con ello un aumento de la desocupación y subocupación de la población económicamente activa. El desempleo abierto parece haberse duplicado en cada década, a partir de 1940, para alcanzar aproximadamente 100000 individuos en 1970 , y saltar a 220000 en 1974. Por lo que toca al subempleo, se estimó que en 1970 alcanzaba al 35\% de la población económicamente activa del Distrito Federal (Hewitt de Alcántara, 1977). Se estima que para 1978, el subempleo ascendió a $47.6 \%$ de la PEA. 5

El Estado ha iniciado un nuevo programa de financiamiento de vivienda que ha repercutido en el funcionamiento del mercado inmobiliario, aunque tal programa se dirige, básicamente, a sectores medios. Los estratos populares no tienen otro remedio que invadir terrenos, ocupar tierras ejidales o comunales 6 en forma ilegal o transformarse en víctimas de especuladores inescrupulosos (tolerados y a veces apoyados por la administración pública) al comprar terrenos en fraccionamientos al margen de la ley. Las ocupaciones ilegales se llevan a cabo sobre todo en la zona noreste del Estado de México, cercana al Vaso de Texcoco, la zona más inhóspita del Valle de México, integrada por tierras inundables, salitrosas e insalubres, poco atractivas para la explotación agrícola o el asentamiento de estratos sociales más favorecidos.

A fines de los años sesenta, las contradicciones sociales, generadas por el incremento de los problemas señalados, se vuelven más violentas en el panorama urbano. Es entre 1968 y 1972 que aumentan notablemente las invasiones de terrenos por parte de organizaciones independientes y de líderes oficiales, así como los movimientos reivindicativos en torno al mejoramiento de las colonias populares, las que, en general, no disponen de muchos de los servicios básicos.

5 Se entiende aquí por subempleado al trabajador que gana menos del salario mínimo o no tiene empleo permanente. Los datos para 1978 fueron deducidos a partir de Información básica sobre la estructura del empleo y el des. empleo en las Areas Metropolitanas de la ciudad de México, Guadalajara y Monterrey. Secretaría de Programación y Presupuesto, 1979.

${ }^{6}$ Los terrenos ejidales y comunales son propiedad de la nación, y se entregan en usufructo a los campesinos. Tales terrenos no pueden ser enajenados y sólo pueden pasar a usos urbanos, de utilidad pública o interés social, mediante la expropiación. Véase M. Schteingart, "La tierra rural de propiedad social y la lógica capitalista del desarrollo urbano. El caso de México", en La tierra, recurso estratégico para el desarrollo rural y urbano. SIAP, 1983. 
A partir de 1970, el Estado interviene de manera más efectiva en la economía; el gasto público no sólo se destina a la construcción de infraestructura para la acumulación de capital, sino también al desarrollo social a través de la promoción de centros de salud, educación y de nuevos programas de vivienda para los trabajadores. Sin embargo, esas políticas sociales mostraron su carácter contradictorio y su insuficiencia para atacar los serios problemas que pretendían resolver. Por ejemplo, los programas de los Fondos de la Vivienda, si bien han significado un cambio importante en la intervención del Estado respecto del financiamiento y una nueva posibilidad para los trabajadores de acceder a una vivienda digna, producen con cantidades muy limitadas, si se toma en cuenta la demanda, la cual aumentó enormemente a raíz del gran crecimiento urbano.

Otro programa importante que afectó la situación habitacional de los sectores populares, fue el que creó un importante aparato para la regularización de la tenencia de la tierra en los asentamientos precarios. También los resultados de este programa son contradictorios, pues aunque ha servido para introducir servicios y mejorar las condiciones de esos asentamientos, ha provocado, al mismo tiempo, el encarecimiento del terreno y el rechazo de las familias más pobres, las cuales no pueden enfrentar los costos de la regularización.

En 1970 , se estimaba que el $30 \%$ de la población del Distrito Federal habitaba en colonias populares; en 1975 esa estimación ascendió al $40 \%$. Si se considera a la metrópoli en su conjunto, esto es, incluyendo la parte que se localiza en el Estado de México, probablemente la proporción alcanzaría el 50\% (no existen estimaciones oficiales más recientes).

Las clases medias se han asentado, en gran medida en fraccionamientos privados establecidos con fines de lucro: entre 1960 y 1977 fueron aprobados, en diferentes municipios del Estado de México, unos 150 fraccionamientos que cubren aproximadamente el $36 \%$ del crecimiento de la mancha urbana en ese estado. La mayor parte de tales operaciones fueron promovidas por empresas privadas que comenzaban a desarrollar sus negocios inmobiliarios a fines de los sesenta, y que conformaron un importante sector promocional que se expandió y modificó en los setenta gracias al creciente apoyo del Estado (Schteingart, 1983:53).

Pero, por supuesto, el crecimiento metropolitano fue mucho mayor en las colonias populares, las cuales ocupan aproximadamente el $64 \%$ del área urbanizada.

En los últimos años, las políticas urbanas, sobre todo en el Distrito Federal, parecen haber sido menos contradictorias y más clara- 
Cuadro 4. Crecimiento de la población en la zona metropolitana de la ciudad de México (1940-1980)

\begin{tabular}{|c|c|c|c|c|c|c|c|c|c|}
\hline \multirow{2}{*}{$\begin{array}{l}\text { Subdivisiones } \\
\text { territoriales }\end{array}$} & \multirow[b]{2}{*}{1940} & \multirow[b]{2}{*}{1950} & \multirow[b]{2}{*}{1960} & \multirow[b]{2}{*}{1970} & \multirow[b]{2}{*}{1980} & \multicolumn{4}{|c|}{ Tasa anual de crecimiento } \\
\hline & & & & & & 1940.1950 & $1950-1960$ & $1960-1970$ & $1970-1980$ \\
\hline $\begin{array}{l}\text { Ciudad de México } \\
\text { Distrito Federal } \\
\text { Estado de México }\end{array}$ & $\begin{array}{l}1448422 \\
1670314\end{array}$ & $\begin{array}{r}2123785 \\
2931542 \\
29144\end{array}$ & $\begin{array}{r}2670925 \\
4833102 \\
233764\end{array}$ & $\begin{array}{l}2867755 \\
6963286 \\
1907003\end{array}$ & $\begin{array}{l}2812074 \\
9373353 \\
5071647\end{array}$ & $\begin{array}{l}3.8 \\
5.8 \\
7.2\end{array}$ & $\begin{array}{r}2.3 \\
4.8 \\
12.1\end{array}$ & $\begin{array}{r}0.7 \\
3.7 \\
17.8\end{array}$ & $\begin{array}{r}-0.2 \\
2.9 \\
9.9\end{array}$ \\
\hline Zona metropolitana & 1670314 & 2960686 & 5144462 & 8889100 & 14445000 & 5.9 & 5.2 & 5.4 & 4.8 \\
\hline
\end{tabular}

${ }^{a}$ La "ciudad de México estaba formada hasta 1970 por 12 cuarteles que posteriormente se agruparon en 4 delegaciones en el centro de la ciudad: Benito Juárez, Cuauhtế-

moc, Miguel Hidalgo y Venustiano Carranza". be número de municipios del estado de México que pasaron a formar parte de la zona metropolitana son: uno en 1950; dos en 1960; 10 en 1970 y 12 en 1980.
Fuente: Censos Generales de Población de 1940, 1950, 1960 y 1970. Las cifras de 1980, de SPP-CONAPO, Datos básicos sobre la población de México, 1980-2000, Méxi-
co, 1982. 
mente orientadas hacia la obtención de una ciudad más "eficiente", mejor equipada (a costa de una fuerte deuda externa destinada a la creación de obras de provisión de agua, drenaje, transporte), sin invasiones de terrenos (en los últimos tiempos que han sido fuertemente reprimidas), y con sus colonias populares regularizadas (muchas veces en desmedro de los sectores más pobres).

Los programas de vivienda del Estado, aún en los años de "bonanza petrolera", se han vuelto cada vez más limitados, tanto por el número de viviendas producidas como por las reducidas posibilidades que ofrecen a los sectores más necesitados de la población de acceder a las mismas. Por ejemplo, estudios recientes han mostrado un estancamiento en la producción habitacional, incluso la de los organismos especializados más importantes, y una reducción de los sectores con mayor acceso a una vivienda mínima, en desmedro de las mayorías de menores ingresos. Incluso la autoconstrucción se vuelve cada vez más difícil para esos grupos y la renta de cuartos, en viviendas de asentamientos populares, comienza a imponerse como una forma difundida de expoliación urbana (Schteingart, 1984).

Se ha observado, asimismo, un apoyo cada vez más importante por parte del Estado, al sector inmobiliario capitalista, en el que se hace cada vez más evidente un aumento ostensible del dominio de grandes empresas y del capital financiero. Sin embargo, las empresas de capital extranjero que actúan en este sector son muy pocas. Sólo se ha podido detectar, en el mercado habitacional, la presencia de una empresa alemana (vinculada a los sindicatos de ese pais), de otra norteamericana (ligada al sector naviero) y de una tercera, italiana (vinculada al Vaticano). La producción de las mismas tiene poco peso en el conjunto de la actividad del sector promocional en la ciudad.

En el caso de México, la necesidad de encontrar nuevos y variados campos de inversión para el gran capital, así como su inclinación hacia el sector inmobiliario, se ha evidenciado más en los grandes grupos económicos nacionales que en las corporaciones multinacionales.

En sintesis, la lógica de producción del marco citadino construido, destinado a diferentes estratos sociales, ha dado como resultado una enorme extensión del "tejido" urbano, una fuerte división social del espacio y un aumento permanente de la distancia entre lugares de vivienda y centros de trabajo.

Algunos estudios han mostrado que en 1970, en las áreas más pobres de la ciudad, sólo el $28 \%$ de las viviendas contaba con agua entubada en su interior; el índice de hacinamiento era de $2.96 \%$; el promedio de habitantes por médico de 3300 , y más del $45 \%$ de la población viajaba durante más de una hora para llegar de su vivienda 
Cuadro 5. Ciudad de México: áreas socioeconómicas según indicadores de educación, salud, vivienda y alimentación, $1970^{\mathrm{a}}$

\begin{tabular}{lccccc}
\hline Áreas & $\begin{array}{c}\text { Población con } \\
\text { educación básica (5) }\end{array}$ & $\begin{array}{c}\text { Personas por } \\
\text { médico }\end{array}$ & $\begin{array}{c}\text { Viviendas con } \\
\text { agua entubada } \\
\text { (\%) }\end{array}$ & $\begin{array}{c}\text { Personas por } \\
\text { cuarto }\end{array}$ & $\begin{array}{c}\text { Población con subconsumo } \\
\text { de carne, huevos y leche } \\
\text { (\%) }\end{array}$ \\
\hline Área I & 59.5 & 436 & 64.2 & 1.70 & 22.1 \\
Área II & 50.3 & 1078 & 43.7 & 2.25 & 28.9 \\
Área III & 42.6 & 977 & 48.6 & 2.29 & 31.6 \\
Área IV & 48.5 & 2938 & 42.1 & 2.55 & 37.0 \\
Área V & 42.4 & 1680 & 46.5 & 2.42 & 46.7 \\
Área VI & 31.2 & 3322 & 27.8 & 2.96 & 46.3
\end{tabular}

${ }^{a}$ Las seis áreas socioeconómicas fueron determinadas con base en cinco variables: porcentaje de población económicamente activa por niveles de ingreso; ocupación, educación, agua entubada y porcentaje de personas en las viviendas. Cada área esta constituida por un conjunto de cuarteles, delegaciones y municipios de la zona metropolitana. El área I es la de mayor nivel socioeconómico y la Vlla de menor.

Fuente: "La ciudad y el medio ambiente. El caso de la ciudad de México", El Colegio de México, México, 1983. 
hasta su lugar de trabajo. Estos datos contrastan con los de las zonas más afluentes (véase cuadro 5). Por otra parte, se observa un aumento de la segregación urbana, en la medida que los grupos pobres cohabitan cada vez menos, en las mismas delegaciones del Distrito Federal, con los de mejores niveles de ingreso; aquéllos son segregados en municipios periféricos en los que se asienta, de manera casi exclusiva, la población más desfavorecida (Ibarra, Puente, Schteingart, 1983:107).

Esa lógica de "producción", y la consecuente estructura desequilibrada y desigual del espacio, se deben a la acción de una serie de agentes y procesos sociales (generación de rentas del suelo, políticas del Estado, estrategias de sectores capitalistas nacionales y locales) que, aunque articulados de manera indirecta al sistema económico mundial, están más estrechamente vinculados a la dinámica nacional y local que a las estrategias de las empresas multinacionales.

Por ejemplo, el hecho de que las oficinas de esas corporaciones o las residencias de su personal se ubiquen en las áreas más elegantes de la ciudad, no significa que constituyan un factor generador de la división social del espacio; más bien siguen la pauta ya establecida por los factores condicionantes apuntados con anterioridad.

\section{¿ES LA CIUDAD DE MÉXICO UNA METR ÓPOLI MUNDIAL?}

En la cima de la jerarquía urbana mundial, constituida por ciudades de los países centrales, de la semiperiferia y de la periferia, se encuentra un pequeño número de áreas urbanas que conforman los centros fundamentales de la economía, y que se han denominado ciudades mundiales (Hall, 1977; Friedmann y Wolff, 1982). Éstas se caracterizan no por la cantidad de su población, sino más bien, por el control económico y político que ejercen, factor que les permite articular las economías nacionales a la economía mundial. Las ciudades mundiales cumplen funciones comerciales y financieras, ideológicas y administrativas que les confieren el carácter de centros de decisiones economicopolíticas y, por lo tanto, se constituyen en "una manifestación material de ese control" (Friedmann y Wolff, 1982:311).

El presente artículo, en el cual nos hemos referido sólo a la ciudad de México, se basa en investigaciones propias y no nos ha sido posible disponer de la información necesaria para incorporar todos los elementos de la compleja caracterización de ciudad mundial propuesta por Friedmann y Wolff (1982). En el análisis del proceso de industrialización de la ciudad de México, sin embargo, hemos constatado que el capital transnacional domina alrededor de la tercera parte de la producción industrial de la urbe. Si se toma en cuenta que prác- 
ticamente la totalidad de dicha producción se destina al mercado interno, resulta evidente que la capital mexicana influye en la división global del trabajo y de los mercados solamente en el ámbito nacional. La ciudad de México es el centro principal en que se localiza la prođucción transnacional que satisface las necesidades del mercado local, y en ese sentido las barreras nacionales imperan sobre lo que sería la lógica espacial global del capital transnacional. En el sector inmobiliario, en cambio, no existen importantes inversiones extranjeras, a pesar de que dicho sector se ha transformado en los últimos años en un campo atractivo para el gran capital nacional.

Por lo demás (y a pesar de no haber trabajado la información específica, particularmente la referente al sector bancario y de servicios) creemos difícil poder tipificar a la capital mexicana como ciudad mundial, no obstante que, desde el punto de vista demográfico se encuentre en la cima de la jerarquía urbana mundial.

En efecto, la ciudad de México no es sede de matrices de corporaciones internacionales, las que, por lo general, se establecen en los grandes centros de poder de los países centrales. Su importancia como productora de mercancías para el mercado mundial es casi nula, dado que el país destaca como productor de hidrocarburos y minerales (petróleo, plata, etc.), productos que no se generan ni exportan en y desde la ciudad de México, por no ser puerto y localizarse en el centro del país.

- QQuizás podría afirmarse que las ciudades importantes de los países subdesarrollados (como el caso de México), son en general, más receptoras que generadoras de capital, de productos industriales, de cultura. Así, su integración a la economía mundial en términos de subordinación, dificultará su transformación en ciudades mundiales, y las constriñe a desempeñar el papel de metrópolis periféricas. Como tal, la capital mexicana constituye el centro principal de la configuración del espacio nacional, ocupa un lugar destacado dentro del proceso de industrialización del país y se puede afirmaque cumple también una función importante en el plano regional (sobre todo por lo que se refiere a Centroamérica). Tales funciones se inscriben a su vez en un marco más general de relaciones económicas internacionales. Sin embargo, esta vinculación no tiene resultados directos y fácilmente apreciables en el estudio del consumo y la organización del espacio urbano.

Nuestra exposición ha privilegiado los mecanismos y la acción de los agentes internos, enfatizando las contradicciones sociales (desequilibrios, carencias, etc.) que se dan conjuntamente con un fuerte proceso de crecimiento e industrialización, y no ha intentado negar 
la importancia de los factores externos sobre los fenómenos considerados. Pero esa articulación debe ser analiząa evitando las simplificaciones y reducciones metodológicas que caracterizan, por ejemplo, a la hoy tan criticada teoría de la dependencia.

\section{Bibliografía}

BASSOLS BATALLA, Ángel, México: formación de regiones económicas. Instituto de Investigaciones Económicas, UNAM, México, 1979.

BoURNE, L.S., Urban Systems. Clavedon Press, Oxford, Gran Bretaก̃a, 1975.

BROADBENT, Thomas A., Planning and Profit in the Urban Economy. Methuen \& Co., LTD, Gran Bretaña, 1977.

FA JNZYLBER F. y Martínez-Tarrago, I., Las empresas transnacionales. Fondo de Cultura Económica, México, 1976.

FRIEDMANN J. y Wolff G., "World City Formation: an agenda for research and action", International Journal of Urban and Regional Research. vol. 6, núm. 3, 1982.

GARZA, Gustavo, Industrialización de las principales ciudades de México. El Colegio de México, México, 1980.

, "El proceso de industrialización de la ciudad de México: 1845-2000", Lecturas del CEESTEM, vol. 1, núm. 3, 198i.

, El proceso de industrialización de la ciudad de México (1821-1970). Condiciones Generales de la producción y concentración espacial en el capitalismo (mimeo), Centro de Estudios Demográficos y de Desarrollo Urbano, El Colegio de México, México, 1983.

Glickman, Norman J., The Japanese Urban Systems During a Period of Rapid Economic Development. International Institute for Applied Systems Analysis, Austria, 1977.

GotTmanN, Jean, Megalópolis, The MIT Press, Cambridge, Massachusetts, EUA, 1961.

HALL, Peter, The World Cities. Weisenfeld y Nicholson, Londres, 1977, segunda edición.

HewitT DE ALCÁNTARA, Cynthia, "Ensayos sobre la satisfacción de necesidades básicas del pueblo mexicano", Cuadernos del CES, núm. 21, El Colegio de México, México, 1977.

IBARRA, V., Puente S., Schteingart M., La Ciudad y el Medio Ambiente. El caso de la ciudad de México (mimeo), El Colegio de México, México, 1983. 
MagalHaEs, Cordeiro A.L., La concentración industrial en México, estudio de caso, la región central, 1965-1975. (Tesis de maestría), Centro de Estudios Demográficos y de Desarrollo Urbano. El Colegio de México, México, 1982.

SCHTEINGART, Martha y Jaramillo Samuel, "Capital accumulation and housing production in Latin-America, 1960-1980", en Walton John (Ed.), Capital and Labour in the Urbanized World, Sage Publications, Gran Bretaña, 1985.

, "El sector inmobiliario y la vivienda en la crisis". Comercio Exterior, núm. 8, vol. XXXIV, agosto de 1984.

"La promoción inmobiliaria en el área metropolitana de la ciudad de México (1960-1980)", Demografía y Economia, vol. XVIII, 1983.

Thampson, I.B., The Paris Basin. Oxford University Press, Gran Bretaña, 1973.

UNIKEL, L., Ruiz C. y Garza, G., El desarrollo urbano de México. Diagnóstico e implicaciones futuras. El Colegio de México, México, 1976. 